\title{
OUTCOME OF ANTERIOR CRUCIATE LIGAMENT RECONSTRUCTION: A COMPARISON BETWEEN BIOTRANSFIX SCREW AND ALL-INSIDE TECHNIQUE
}

\author{
Nik Alyani Nik Abdul Adel ${ }^{1}$, Mohd Shukrimi bin Awang ${ }^{1}$ and Zamzuri bin Zakaria ${ }^{1}$ \\ ${ }^{1}$ Department of Orthopaedic, Trauma and Rehbilitation, International Islamic \\ University Malaysia, Kuantan, Pahang, Malaysia.
}

Presenter: Nik Alyani Nik Abdul Adel, nikalyani@yahoo.com

Introduction: Anterior cruciate ligament $(A C L)$ reconstruction has evolved during past decade. All inside technique is introduced aiming for less invasive procedure, bone stock preservation, preservation of tendon at its donor site, better graft positioning and fixation technique. This study is conducted to compare the outcomes of this new technique to the previous biotransfix screw.

Materials and method: A cross sectional study was conducted in patients with ACL injury treated with $A C L$ reconstruction surgery in Hospital Sultanah Nur Zahirah, Kuala Terengganu and Hospital Kemaman, Terengganu. Functional outcome with International Knee Documentation Committee (IKDC) score, SF-36 quality of life score and time taken to return to normal activities were evaluated at 18 to 24 months post-operative.

Results: Forty patient were recruited, 20 in each group. Of this, 37 were male with age of $25 \pm 6.48$ years old. 25 were office worker and the rest were field worker. $37.5 \%$ were smoker. Patients in biotransfix screw technique operated at $21.3 \pm 12.6$ months after the injury while those in all inside technique at $17.7 \pm 11.9$ months( $p$-value 0.35$)$. BMI was $24.58 \pm 4.59$. The SF-36 score were similar in both groups with $p$-value 0.59 . Both groups have same IKDC score of $82.99 \pm 12.55$. Time taken to return to normal activity level was $46.3 \pm 19.7$ weeks which was similar in both groups( $p$-value 0.943 ). Re rupture rate were $10 \%$ in biotransfix screw technique and $5 \%$ in all inside technique. None of them has any form of infection. There were no correlation between quality of life SF-36 score with age, tobacco use, BMI, duration of injury until operation and occupation of the patient in both techniques.

Conclusion: The functional outcome, quality of life and time return to normal activity were similar between patients who had biotransfix screw and all inside technique. There were also no correlations between factors studied with quality of life in both groups. 